\title{
LISTA DAS ESPÉCIES DE DENDROBRANCHIATA E CARIDEA (CRUSTACEA, DECAPODA) DO MUSEU DE HISTÓRIA NATURAL CAPÃO DA IMBUIA, CURITIBA E DO CENTRO DE ESTUDOS DO MAR, PARANAGUÁ, PARANÁ, BRASIL
}

\author{
Elaine de Azambuja Corrêa ${ }^{2}$ \\ Jayme de Loyola e Silva ${ }^{2}$
}

\begin{abstract}
Species list of Dendrobranchiata and Caridea (Crustacea, Decapoda) from the Collections of Museu de História Natural Capão da imbuia, Curttiba and Centro de Estudos do Mar, Paranaguá, Paraná, Brazil. Due to its biogeographical characteristics, the coast of the State of Paraná reveals to be a very important area for zoological researches. At the present time, however, there are only a few studies related to its carcinological fauna. The Museu de História Natural Capão da Imbuia which belongs to the Curitiba City Hall and the Centro de Estudos do Mar, of the Universidade Federal do Paraná have Crustacea collections, which are the unique references to the State. This research paper was based on the files of these institutions and also on bibliographical survey. The present research contains a detailed report of the collections and a catalogue of Dendrobranchiata and Caridea (Crustacea) species, including typical locality and geographical distribution of them.
\end{abstract}

KEY WORDS. Decapoda, Dendrobranchiata, Caridea, species list, Paraná, Brazil

O litoral do Paraná, como o de muitos outros Estados, é de grande importância para estudos zoológicos. Apesar de sua pequena extensão, $107 \mathrm{Km}$, é formado por ambientes distintos como praias arenosas, costões rochosos e formações de mangrovia, representados por associações florísticas e faunísticas típicas (BIGARELLA 1978)

Como consequência desses ambientes distintos, no contexto biogeográfico nacional, o litoral paranaense localiza-se no centro de uma região de transição hidrológica e conseqüentemente faunística (MELO 1985; LANA 1987; MELO et al. 1989).

No Paraná somente duas instituições trabalharam na coleta de crustáceos. O Museu de História Natural Capão da Imbuia (Curitiba), mais antigo, possui a maior coleção. O Centro de Estudos do Mar (Paranaguá), apesar de instituição mais nova, possui coleção bem representativa.

O material zoológico resultante de inúmeras coletas e de exemplares doados, inclusive de outros Estados, em sua maioria, está depositado no Museu de História Natural Capão da Imbuia (MHNCI), sob a guarda da Secretaria do

1) Contribuição número 820 do Departamento de Zoologia, Universidade Federal do Paraná.

2) Departamento de Zoologia, Universidade Federal do Paraná, Caixa Postal 19020, 81531-990 Curitiba, Paraná, Brasil. Bolsistas do CNPq. 
Meio Ambiente da Prefeitura Municipal de Curitiba. Este Museu originou-se do antigo Museu Paranaense, que foi fundado em 25 de setembro de 1876, e as coleções constituíam-se de moluscos, crustáceos, ofídios, peixes e mamíferos. Embora bem representadas, denotam a ausência de caráter científico, visto possuírem apenas a procedência.

Segundo CORDEIRO \& CORRÊA (1986) e MirandA \& CORRÊA (1992) a partir de 1906, teve início a organização e a etiquetagem das coleções. Apenas em 1937, passaram a configurar nos moldes científicos, com o trabalho de colaboração de eminentes especialistas de outras partes do Brasil e do mundo.

Nas primeiras viagens organizadas por técnicos do Museu ao litoral paranaense, realizadas a partir de 1942 em caráter científico, foi iniciada a Coleção de Crustacea que se encontra registrada no atual Livro Tombo. O botânico Ralph J.G. Hertel e o taxidermista André Mayer foram os responsáveis por este pioneirismo.

Em 1946, Rudolf Bruno Lange e Carlos N. Gofferjé passaram a fazer parte do Museu Paranaense, o primeiro como técnico e o segundo como auxiliar voluntário. Gofferjé iniciou seus estudos malacológicos e também participou das coletas de Crustacea.

A partir de 1974, as coleções foram mantidas graças a ajuda de técnicos do Museu que deram continuidade às coletas e à manutenção. Nesta mesma época iniciaram-se os estudos das águas interiores em nosso estado, de onde procederam muitos exemplares hoje presentes no atual acervo.

No ano de 1976 o Museu de História Natural foi transferido da Secretaria de Agricultura do Estado do Paraná para a Prefeitura Municipal de Curitiba, Divisão de Zoologia e Geologia do Departamento de Parques, Pragas e Preservação Ambiental.

A partir de 1986, as coletas e a manutenção dos Crustáceos, ficaram sob responsabilidade da estagiária Maritza Carla de Oliveira com o apoio da bióloga Valéria Gomes Veloso que se dedicaram à organização dos Brachyura. Colaboraram com aumento do acervo da coleção os estagiários M.R. Cury; Magno Vicente Segalla; Vanessa Persson e Wolmar B. Wosiacki.

Em julho de 1987, iniciaram-se os trabalhos para a organização da coleção de camarões (Dendrobranchiata e Caridea) sob a responsabilidade da primeira autora.

O Centro de Estudos do Mar possui apreciável coleção de Crustacea que foi tombada em 1992. Esta coleção foi formada a partir de exemplares identificados pelo professor Gustavo A. S. de Melo, do Museu de Zoologia da Universidade de São Paulo, para o laboratório de Zooplâncton (Projeto Meroplâncton). Faz parte do acervo o material bentônico coletado na baía de Paranaguá, "N. Oc. Almirante Saldanha" Operação SUESTE. A coleção, atualmente, consta de mais de 700 lotes.

Sabendo-se da importância do litoral do Estado, por suas características biogeográficas e da necessidade de informações sobre a fauna carcinológica, objetiva este trabalho, apresentar um catálogo das espécies de camarões do Paraná, que fazem parte do acervo dessas duas coleções. 


\section{MATERIAL E MÉTODOS}

Foram analisados 688 exemplares, representados por nove famílias, 14 gêneros e 22 espécies.

O material listado pertence às coleções do Museu de História Natural Capão da Imbuia (MHNCI) Curitiba e do Centro de Estudos do Mar da Universidade Federal do Paraná (CEM/UFPR) Paranaguá (Pontal do Sul).

Os exemplares da coleção do MHNCI, em sua maioria, foram coletados ao acaso por pesquisadores de outras áreas, sem metodologia definida e, muitas vezes, com dados insuficientes. Para algumas espécies tivemos o cuidado de preparar as peças e confeccionar os desenhos mais importantes para a classificação.

Esta coleção abrange ainda espécimes das diferentes fases de coletas da Operação SUESTE, N. Oc. Almirante Saldanha, efetuadas em Santos (São Paulo), litoral do Paraná e Ilha de Santa Catarina (Santa Catarina), nos anos de 1982 a 1985. Os lotes foram organizados por espécie, data de coleta e procedência, com o intuito de facilitar a localização dos exemplares na coleção. Foram registrados no livro de Tombo da Instituição, com informações sobre: procedência, identificação, família, data de coleta, coletor, número de exemplares, sexo, determinador e data da determinação. Ao contrário da antiga, a coleção proveniente da Operação SUESTE, foi organizada dentro dos moldes atuais exigidos.

Devido a determinados indivíduos estarem danificados, foi possível a identificação somente a nível de família.

Para a coleção do CEM foram analisados 39 exemplares dos quais 38 foram identificados a nível de espécie e um a nível de gênero, por se encontrar danificado. Alguns espécimes desta coleção, não possuíam procedência exata mas, foram coletados no litoral do Paraná, em regiões próximas praia de Pontal do Sul, motivo pelo qual foram mantidos.

O material tombado é proveniente, principalmente, dos laboratórios de Zooplâncton e Bentos do CEM. Os indivíduos foram organizados em lotes e no registro constam: procedência, data, coletor, horário, maré, tipo de fundo, condições climáticas, profundidade, número de indivíduos, identificação, nome vulgar e determinador.

Os exemplares de ambas as coleções estão conservados em álcool $70 \%$ e informatizados.

Embora as coleções não tenham sido elaboradas dentro do contexto metodológico atual, com exceção da SUESTE, são as únicas que referenciam a fauna de camarões para o Estado.

A lista de espécies foi organizada com base nos trabalhos de FAUSTO-FILHO (1966) e Melo et al. (1989). 


\section{RESULTADOS}

\section{Solenoceridae \\ Pleoticus muelleri (Bate, 1888)}

Localidade-tipo. Saint Thomas, Ilhas Virgens, Caribe.

Distribuição. Carolina do Norte (USA) até a Baía Campeche e Ilha Antigua; América Central até a Costa Rica, Brasil (Espírito Santo, Rio de Janeiro, São Paulo, Paraná, Santa Catarina, Rio Grande do Sul). Uruguai e Argentina.

Material examinado. SUESTE I (estação $6090,26^{\circ} 14^{\prime} 08^{\prime \prime} \mathrm{S}-48^{\circ} 18^{\prime}$ 09"W), um macho (MHNCI-94)

\section{Penaeidae \\ Penaeus (Litopenaeus) schmitti Burkenroad, 1936}

Localidade-tipo. Kingston Bay, Jamaica.

Distribuição. Cuba, Jamaica, Haiti, San Domingo, Panamá, Colômbia, Venezuela, Guianas e Brasil (do Rio de Janeiro até Laguna em Santa Catarina).

Material examinado. BRAsIL, Paraná: Guaraqueçaba, quatro fêmeas, quatro machos (MHNCI-1); Matinhos, um macho (MHNCI-7); (Caiobá), duas fêmeas, um macho (MHNCI-2); um macho (MHNCI-5); Guaratuba (rio Cubatão, Baía de Guaratuba), uma fềmea (MHNCI-3); Volta Grande, uma fềmea, dois machos (MHNCI-4); Paranaguá, uma fêmea (MHNCI-8); uma fêmea, dois machos (CEM); Guaraqueçaba, uma fềmea, um macho (CEM). Santa Catarina: Cam- boriú, um macho (MHNCI-6); Ubatuba, uma fềmea (MHCI-9).

\section{Penaeus (Farfantepenaeus) paulensis Perez Farfante, 1967}

Localidade-tipo. Santos, São Paulo, Brasil.

Distribuição. Brasil, sul de Cabo Frio (Rio de Janeiro) até Mar del Plata (Argentina).

Material examinado. BRASIL, Paraná: Guaraqueçaba (Ilha do Pinheiro), um macho, uma fêmea (MHNCI-10); Volta Grande, uma fêmea (MHNCI-11); Paranaguá, uma fêmea (MHNCI-12).

Penaeus (Farfantepenaeus) brasiliensis Latreille, 1817

Localidade-tipo. costa do Brasil.

Distribuição. Cabo Hatteras, Carolina do Norte (USA); Bermudas; Tortugas, Flórida; Bahamas; Antilhas, México e Brasil (até o Rio Grande do Sul).

Material examinado: uma fềmea (CEM).

\section{Xiphopenaeus kroyeri (Heller, 1862)}

Localidade-tipo. Rio de Janeiro, Brasil.

Distribuição. Desde o sul do Cabo Hatteras - Carolina do Norte (USA) até a Baía de Zimbros - Santa Catarina (Brasil). 
Material examinado. BRAsIL, Paraná: Matinhos, 38 machos, 44 fềmeas (MHNCI-13); Guaratuba (rio Cubatão, Baía de Guaratuba), uma fêmea (MHNCI-14); Matinhos, quatro machos, três fêmeas (MHNCI-15); três machos (MHNCI-16); Paranaguá (Pontal do Sul), duas fềmeas (MHNCI-18); Matinhos (Caiobá), uma fềmea (MHNCI-19). Santa Catarina: Ubatuba, uma fềmea (MHNCI-17).

\section{Artemesia longinaris Bate, 1888}

Localidade-tipo. Altura de Montevidéo, Uruguai.

Distribuição. Desde o Rio de Janeiro, Brasil até Rawson, Argentina.

Material examinado. Brasil, Paraná: Paranaguá (Pontal do Sul), seis fêmeas, um macho (MHNCI-20).

\section{Trachypenaeus constrictus (Stimpson, 1871)}

Localidade-tipo. Beaufort, Carolina do Norte (USA).

Distribuição. Golfo do México, Caribe e Brasil até a baía de Zimbros (Santa Catarina).

Material examinado. BRASIL, Paraná: Matinhos, um macho (MHNCI-21).

\section{Sicyonidae}

Sicyonia dorsalis Kingsley, 1878

Localidade-tipo. Forte Jefferson, Flórida (USA).

Distribuição. Cabo Hatteras, Carolina do Norte (USA); Golfo do México e da Colômbia até a Guiana Francesa; Brasil (do Ceara até Santa Catarina).

Material examinado. Brasil, Paraná: Paranaguá (bóia 22 do canal de acesso ao Porto de Paranaguá), nove fêmeas, quatro machos (CEM).

\section{Sicyonia typica (Boeck, 1864)}

Localidade-tipo. Molde Fjord, costa da Noruega. Esta localidade não foi confirmada, segundo WILLIAMS (1984).

Distribuição. Carolina do Norte (USA) até o Golfo do México, Caribe até Santa Catarina (Brasil).

Material examinado. SUESTE II (estação $6258,25^{\circ} 13^{\prime} \mathrm{S}-4^{\circ} 42^{\prime} 05^{\prime \prime} \mathrm{W}$ ),

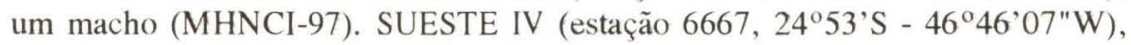
uma fêmea (MHNCI-116).

\section{Sicyonia laevigata Stimpson, 1771}

Localidade-tipo. Charleston, Carolina do Sul (USA).

Distribuição. Cabo Hatteras, Carolina do Norte (USA); Caribe até a Colômbia e Brasil (Santa Catarina); Pacífico oriental: Panamá.

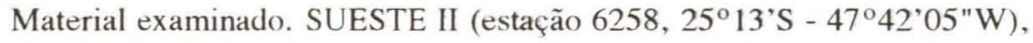
um macho (MHNCI-99). 


\section{Pasiphaeidae}

Leptochela (Leptochela) serratorbita Bate, 1888

Localidade-tipo. Saint Thomas, Virgin Islands, Caribe.

Distribuição. Carolina do Norte, Carolina do Sul e Flórida (USA); Golfo do México; Caribe; América Central até a Costa Rica; Brasil (até o Rio Grande do Sul).

Material examinado. SUESTE I (estação 6107, 253' $5^{\prime \prime} \mathrm{S}$ - 484’4"W), uma fêmea (MHNCI-95). SUESTE II (estação 6258, $25^{\circ} 13^{\prime} \mathrm{S}$ - 47²4' 5"W), uma fêmea (MHNCI-98). SUESTE III (estação 6373, 26³'4"S - 48¹3'51"W), duas fêmeas sendo uma ovada (MHNCI-104). SUESTE IV (estação 6635,

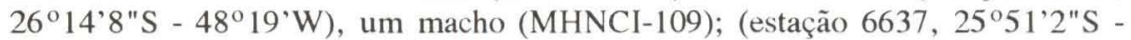
$48^{\circ} 51$ '2"W), uma fêmea (MHNCI-110); (estação 6638, 2546'S - 48 12 '8" W),

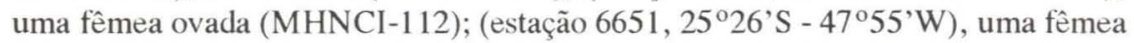
(MHNCI-114); (estação 6652, 253' $5^{\prime \prime S}$ - 484'4"W), uma fêmea (MHNCI-115).

\section{Palaemonidae}

\section{Macrobrachium acanthurus (Wiegmann, 1836)}

\section{Localidade tipo. Costa do Brasil.}

Distribuição. Georgia (USA); Caribe e Brasil (Paraná, Santa Catarina e Rio Grande do Sul).

Material examinado. Brasil, Paraná: Matinhos (rio Caiobá, praia de Caiobá), uma fêmea, dez machos (MHNCI-40); Matinhos (Caiobá), uma fêmea (MHNCI-42); Guaraqueçaba, uma fêmea (MHNCI-43); Guaratuba, uma fêmea ovada (MHNCI-44); uma fêmea (MHNCI-45); um macho (MHNCI-82); Paranaguá (Ilha do Mel, riacho da praia do Farol), um macho (MHNCI-46); um macho (MHNCI-83); Ilha do Superagui (Ponta do Canudal), uma fêmea ovada (MHNCI-47); Maringá (Ribeirão da Rosa, Pedreira Rei Midas), uma fêmea (MHNCI-90); Paranaguá (Pontal do Sul), cinco fêmeas, sendo duas ovadas, seis machos (CEM). Santa Catarina: Canasvieiras, três fêmeas, sendo duas ovadas, dois machos (MHNCI- 38); um macho (MHNCI-39); um macho (MHNCI-41).

\section{Macrobrachium potiuna (Muller, 1836)}

Localidade tipo. Barbados, América Central.

Distribuição. Antilhas, América Central (até a Guatemala) e Brasil (até o Rio Grande do Sul).

Material examinado. Brasil, Paraná: Morretes (Porto de Cima), 11 fềmeas, 11 machos (MHNCI-50); uma fêmea, um macho (MHNCI-58); (rio Cari, Porto de Cima), três machos (MHNCI-59); (rio do Sítio, Porto de Cima), dois machos (MHNCI-66); (rio Mãe Catira), uma fêmea ovada, dois machos (MHNCI-52); (afluente do rio Petinga), 43 fềmeas, sendo seis ovadas, 32 machos (MHNCI-54); (estrada da Graciosa, alto da Serra do Mar), uma fêmea, dois 
machos (MHNCI-65); (rio Nhundiaquara), duas fêmeas ovadas (MHNCI-73); (rio Taquaral, estação Marumbi), 16 fêmeas, 15 machos (MHNCI-84); Antonina, um macho (MHNCI-71); (Rio Biguá), 12 fêmeas, sendo cinco ovadas, 11 machos (MHNCI-51); (Sapitanduva, residência da Biologia), duas fêmeas ovadas (MHNCI- 56); (Ilha do Corisco), um macho (MHNCI-68); Paranaguá (praia de Pontal do Sul), um macho (MHNCI-53); (Ilha do Mel, rio que rodeia o Forte), três fêmeas, dois machos (MHNCI-55); (Ilha do Mel), duas fêmeas, dois machos (MHNCI-57); Matinhos (rio Caiobá, praia de Caiobá), cinco fêmeas, sendo três ovadas, cinco machos (MHNCI-60); (Caiobá), uma fêmea, três machos (MHNCI-61); (praia de Matinhos), uma fêmea, um macho (MHNCI-69); uma fêmea, um macho (MHNCI-72); (riacho Sertãozinho), quatro fêmeas, sete machos (MHNCI-77); Guaratuba (rio Cubatão, baía de Guaratuba), uma fêmea ovada, dois machos (MHNCI-63); (Ilha da Pesca, Baía de Guaratuba), dois machos (MHNCI-64); (praia de Guaratuba), um macho (MHNCI-67); Maringá (pedreira Rei Midas), uma fêmea, um macho (MHNCI-89). Santa Catarina: Palmital (rio das Onças), 24 fềmeas, sendo quatro ovadas, 18 machos (MHNCI-62); Canasvieiras, uma fêmea (MHNCI-70); um macho (MHNCI-74); Florianópolis (Ribeirão da Ilha), um macho (MHNCI-2).

\section{Macrobrachium carcinus (Linnaeus, 1758)}

Localidade tipo. "Americae fluviis". Jamaica segundo HoLthuis (1952).

Distribuição. Flórida (USA), México, América Central, Antilhas até o sul do Brasil (Rio Grande do Sul).

Material examinado. BRAsil, Santa Catarina: Canasvieiras, uma fêmea (MHNCI-48); Florianópolis (Ribeirão da Ilha), um macho (MHNCI-91).

\section{Macrobrachium sp.}

Material examinado. Brasil, Paraná: Matinhos (rio Caiobá, praia de Caiohá), uma fêmea ovada (MHNCI-76); (praia de Matinhos), uma fêmea (MHNCI-79); Guaratuba (rio Cuhatão, baía de Guaratuba), uma fêmea ovada (MHNCI-80); Paranaguá (Ilha do Mel), uma fềmea, um macho (MHNCI-81); (Pontal do Sul), dois machos (CEM); Santa Catarina: Canasvieiras, três fêmeas, sendo duas ovadas, três machos (MHNCI-75); um macho (MHNCI-78).

\section{Palaemon (Palaemon) pandaliformis Stimpson, 1871}

Localidade tipo. Barbados, Caribe.

Distribuição. Antilhas, América Central (até a Guatemala) e Brasil (até o Rio Grande do Sul).

Material examinado. Brasil, Paraná: Paranaguá (rio Perequê, praia de Pontal do Sul), sete fêmeas ovadas, um macho, um jovem (MHNCI-37); (Pontal do Sul), três machos (CEM); Antonina (Fazenda Zoada D'água), uma fêmea, quatro machos (MHNCI-93). 


\section{Palaemon (Palaeander) northropi (Rankim, 1898)}

Localidade tipo. Nassau, New Providence.

Distribuição. Bermudas e Brasil até o Uruguai.

Material examinado. Brasil, Paraná: Morretes (rio do Sítio, Porto de Cima), três fêmeas, dois machos (MHNCI-33); Guaratuba (rio Cubatão, baía de Guaratuba), uma fềmea, um macho (MHNCI-35); Matinhos (Caiobá), uma fêmea (MHNCI-36). Santa Catarina: Canasvieiras, duas fềmeas (MHNCI-34).

\section{Palaemonetes (Palaemonetes) argentinus Nobili, 1901}

Localidade tipo. Rio da Plata, Argentina.

Distribuição. Bacias dos Estados do sul do Brasil (Paraná, Santa Catarina e Rio grande do Sul), do Uruguai e da Argentina

Material examinado. Brasil, Paraná: (estação 7, defronte à foz do rio Maciel, $25^{\circ} 33^{\prime} \mathrm{S}-48^{\circ} 25^{\prime} \mathrm{W}$, numa depressão subaquática, com profundidade máxima de $20 \mathrm{~m}$ ), três fềmeas (CEM).

\section{Lysmatidae}

\section{Exhippolysmata oplophoroides Chace, 1972}

Localidade tipo. Suriname.

Distribuição. Carolina do Norte (USA); Golfo do México, Guianas; Brasil e norte do Uruguai.

Material examinado. Brasil, Paraná: Guaratuba (baia de Guaratuba), uma fềmea (MHNCI-31); Matinhos (praia), quatro fềmeas ovadas (MHNCI-32).

\section{Processidae \\ Processa bermudensis (Rankin, 1900)}

Localidade tipo. Bermudas.

Distribuição. Bermudas, Carolina do Norte, próximo ao Cabo Hatteras até o noroeste da Flórida (USA); Vera Cruz (México); Cuba; Porto Rico; Venezuela e Brasil (Bahia ao Rio de Janeiro e Paraná).

Material examinado. SUESTE I (estação 6076, 26²9’5"S - 48²2’4"W), uma fềmea (MHNCI-96).

\section{Ogyrididae}

\section{Ogyrides alphaerostris (Kingsley, 1880)}

Localidade tipo. Mouth of Far Creek at Engelhard, Hyde County, Carolina do Norte (USA).

Distribuição. Da Virginia até a Luisiania (USA); Brasil (Paraná).

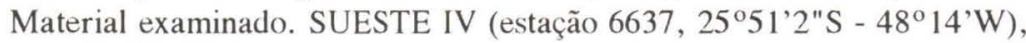
uma fềmea (MHNCI-111). 


\section{Alpheidae \\ Alpheus armillatus Milne Edwards, 1837}

Localidade tipo. Caribe.

Distribuição. Carolina do Norte, Bermudas (USA); Caribe; Brasil (até Cananéia, São Paulo e Paraná).

Material examinado. Brasil, Paraná: Matinhos (praia de Caiobá), três fềmeas, sendo duas ovadas, dois machos (MHNCl-22); Paranaguá (praia de Pontal do Sul), uma fềmea, um macho (MHNCI-26). SUESTE II (estação 6258, 2513'S - 47042'5"W), um macho (MHNCI-100). SUESTE III (estação 6405, 24⒉'S $45^{\circ} 34^{\prime}$ W), uma fềmea ovada (MHNCI-1 18). SUESTE IV (estação 6622, $26^{\circ} 44^{\prime}$ 'S - 48 $25^{\prime} 8^{\prime \prime W}$ ), duas fềmeas, sendo uma ovada (MHNCI-108); (estação 6639, $25^{\circ} 55^{\prime} 4^{\prime \prime} \mathrm{S}-4^{\circ} 52^{\prime} 3^{\prime \prime} \mathrm{W}$ ) duas fềmeas, um indeterminado (MHNCI-113).

\section{Alpheus estuariensis Christoffersen, 1980}

Localidade tipo. Brasil (Foz do rio Potengi, Natal, Rio Grande do Norte).

Distribuição. Costa leste da Flórida (USA); Golfo do México; Cuba; República Dominicana; Trinidad; Curaçao; Brasil (do Ceará até o Paraná).

Material examinado. Brasil, Paraná: Paranaguá (praia de Pontal do Sul), um macho (MHNCI-30); uma fềmea (CEM). SUESTE II (estação 6254,

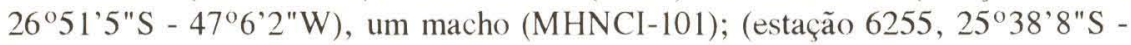
$47^{\circ} 30^{\prime} 2 " \mathrm{~W}$ ), uma fềmea (MHNCI-102).

\section{Alpheus sp.}

Material examinado. Brasil, Paraná: Paranaguá (Ilha do Mel), uma fêmea ovada (MHNCI-24); Matinhos (praia de Caiobá), uma fêmea ovada, um macho

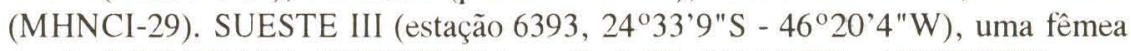

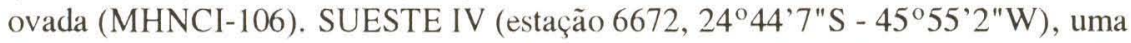
fêmea, um indeterminado (MHNCI-117); (estação CBM\#7, depressão subaquática, defronte à foz do rio Maciel, $\left.25^{\circ} 33^{\prime} \mathrm{S}-48^{\circ} 25^{\prime} \mathrm{W}\right)$, um macho (CEM). Santa Catarina: Canasvieiras, uma fêmea, três machos (MHNCI-27); um macho (MHNCI-28).

\section{DISCUSSÃO E CONCLUSÕES}

Foi dada maior atenção às espécies Macrobrachium acanthurus (Wiegmann 1836) e Palaemon (Palaeander) northropi (Rankin, 1898), já que alguns exemplares apresentavam variações no número de dentes rostrais. Para $M$. acanthurus, uma fêmea apresentou 17 dentes rostrais dorsais, sendo um subapical e 11 dentes ventrais; um macho com 12 dentes dorsais, sendo um subapical e 12 dentes ventrais; dois machos com 13 dentes dorsais, um subapical e 13 dentes ventrais. Todos estes quatro indivíduos apresentavam três dentes rostrais dorsais atrás do limite posterior da órbita, às vezes, com o terceiro dente sobre o limite orbital. Holthuis (1952), WiLliams (1984) e BOND-BUCKUP \& BUCKUP (1989) assinalam que os indivíduos desta espécie apresentam um ou dois dentes rostrais dorsais 
atrás da órbita, nove a 11 dentes dorsais e quatro a sete dentes rostrais ventrais.

Com relação a $P$. (P.) northropi, um dos exemplares estudados apresentou três dentes rostrais ventrais robustos e quatro dentes menores, situados entre o primeiro e o segundo dentes. HolTHUIS (1952) assinala, para a espécie em discussão, a presença de sete a 10 dentes rostrais dorsais e três a quatro dentes robustos na face ventral.

Palaemon (P.) northropi, Processa bermudensis (Rankin, 1900) e Alpheus armillatus Milne Edwards, 1837, constituem novas ocorrências para o Paraná.

\section{REFERÊNCIAS BIBLIOGRÁFICAS}

Bigarella, J.J. 1978. A Serra do Mar e a Porção Oriental do Estado do Paraná. Um problema de Segurança Ambiental e Nacional. Curitiba, Governo do Estado do Paraná, Secretaria de Estado do Planejamento, Associação de Defesa e Ed. Ambiental, 242p.

Bond-Buckup, G. \& L. Buckup. 1989. Os Palaemonidae de águas continentais do Brasil meridional (Crustacea, Decapoda). Rev. Brasil. Biol. 49 (4): 883-896.

CORDEIRO, A.A.M. \& M.F.M. CORRÊA. 1986. Histórico do acervo Ictiológico da Divisão de Zoologia e Geologia da Prefeitura Municipal de Curitiba. Bol. Div. Zool. Geol. 1: 1-8.

Fausto-FIlHo, J. 1966. Primeira contribuição ao inventário dos Crustáceos Decapodos marinhos, do nordeste brasileiro. Arq. Estac. Biol. Mar. Univ. Fed. Ceará 6 (1): 31-37.

Holthuis, L.B. 1952. The subfamily Palaemonidae. A general revision of the Palaemonidae (Crustacea, Decapoda, Natantia) of the Americas, II. Occas. Pap. Allan Hancock Found. Publ. 12: 1-396.

LANA, P.C. 1987. Padrões de distribuição geográfica dos poliquetas errantes (Annelida: Polychaeta) do Estado do Paraná. Ciência e Cultura, São Paulo, 39 (11): 1060-1063.

Melo, G.A.S. 1985. Taxonomia e padrões distribucionais e ecológicos dos

Brachyura (Crustacea, Decapoda) do litoral sudeste do Brasil. Tese de

Doutorado, não publicada, Universidade de São Paulo, São Paulo, 215p.

Melo, G.A.S.; V.G. Veloso \& M.C. Oliveira. 1989. A fauna de Brachyura (Crustacea, Decapoda) do litoral do Estado do Paraná. Nerítica 4 (1/2): 1-31. MirandA, R.B. \& M.F.M. CORRÊA. 1992. Histórico do acervo de malacologia do Museu de História Natural "Capão da Imbuia". Arq. Biol. Tecnol. 31 (1): 37-44.

Williams, A.B. 1984. Shrimps, lobsters and crabs of the Atlantic Coast of the eastern United States, Maine to Florida. Washington, Smithsonian Institution Press, 550p. 